\title{
Transformation Thinking of the Management and Service for College Retirees in the New Era
}

\author{
Yi Li, LiangJun Du, TingTing Zeng, \\ (Southwest Petroleum University, Chengdu, Sichuan Province, China, \\ 610500)
}

Keywords: College retirees, Management and service, Transformation thinking

\begin{abstract}
Under the new situation, the work of management and service of retirees in colleges occupies an important position in the work of harmonious campus construction. This paper analyzes the deficiencies in the management and service of retired personnel in colleges in our country and gives the directions of reform and transformation, including improving management system, promoting service consciousness and establishing network platform to provide some references for the relative researchers.
\end{abstract}

\section{Significance of the Management and Service for College Retirees}

In today's society, people's diverse thinking virtually bring challenges and pressures to the management of retired personnel in Colleges and universities. The pursuit of new things by retirees in colleges will gradually become an ideological burden for managers and increase the difficulty of management. At the same time, because many retirees do not live in the dormitory, they also bring inconvenience to management. In view of this, strengthening the management of University retirement services and optimizing its path become necessary to cope with this diversity and inconvenience situation. There are a part of University retirees after leaving their jobs, due to the surrounding environment caused by great changes, they also show a certain weakening trend in the ideological and political awareness. This tendency causes them not to carry on the ideological and political study well, sticks to the original ideological experience, the behavior consciousness once was derailed with the society, and deviates from the system. In view of this kind of form, the optimization of the University retirement service management will fundamentally enhance the effect and quality of the ideological and political work of the University retirees. Many retirees are faced with the situation when their children are not around after retirement, which is different from the situation with students in the teaching stage, and loneliness and loss are hard to hide. If the development of this emotion, and easy to make the elderly into loneliness and painful depression, will have a negative impact on their health. Therefore, it is of great significance for the construction of harmonious campus to optimize the management and service of the retirees and improve the management and service level.

\section{Main Problems of the Management and Service for College Retirees}

Imperfect Management System. At present, the management of retirement in colleges in China mainly follows the old model before the reform. Colleges and universities work independently and establish retirement management departments, not only between brothers and schools, but also lack communication and experience communication between institutions of higher learning and social pension institutions. The socialization of retirement management is still in the exploratory stage. The completely closed management mode of colleges and universities has brought heavy burden to the management of College retirement, and seriously affected the pace of the rapid development of colleges and universities. In charge of the management of retired Department staff due to busy work, lack of strategic thinking, and prospective study of retired cadres in some key and difficult problems caused by reform and innovation is not strong. The limitations of retirement management allocation 
are not commensurate with the increasingly burdensome management services. The school has only established a school level retirement management office, which manages the retired staff of the whole school, and does not provide retirement management staff for each of the two classes. The work is supervised by the chairman of the trade union branch. The latter, because it is also a number of posts, cannot fully put their energy on retirement management, but just upload the information transfer function. The filing scope of retirement work is not detailed enough to reflect the characteristics of retirement work. The formation of retirement work archives involves many departments and units, so it is fragmented and lacks systematic management. There are no clear management personnel, work plans, post responsibilities, assessment indexes, rewards and punishments methods. This is the reason why some retired veteran comrades full of complaints such disharmonious factors produced. Sometimes there is not timely to find and solve the problem.

Inadequate Service Awareness. The psychological endurance of retirees is very weak, and they are very sensitive to the attitude of the school and the people around them. According to the psychological characteristics of retired officers, retired personnel management department to be patient to do their ideological work, let them read the relevant documents, to participate in the school meeting, listen to the academic report, go out and make them understand the situation of social development and school. At the same time, we should also listen to their opinions and suggestions, mobilize their enthusiasm, and let them truly integrate into the society ideologically and closely follow the social development. Through the organization of colleges and universities, the retired veteran comrades should continue to exert their surplus heat in building a harmonious campus, so that old comrades can eliminate their sense of loss and loneliness in harmonious interpersonal relationships, and they will have laughter and festivals at all times. At present, the status of retirees in most colleges and universities is not optimistic. The lack of staff is serious, and the staff members have aging phenomenon, and the age structure is aging. The uneven quality of personnel, a considerable number of staff due to age is too large, inappropriate for the original job adjustment, work enthusiasm is not high. The retired cadres management service work of political and policy is strong, require staff to have good ideological and political quality, and has the ability to use a certain policy, service management, research on the use of ability and innovation ability. If you cannot do with the cause to keep people, keep people with feelings, with the appropriate treatment to keep people, let more young people love to have both ability and political integrity of retired service work, the work will be few. Therefore, it is necessary to improve the political quality of management service personnel. To help them establish a good sense of professionalism and professionalism and enhance the glorious work of aging, a sense of responsibility.

Backward Working Style. At present, the means of retirement management are still relatively single, and still remain in the purely welfare and service-oriented way. It is difficult to adapt to the diverse needs of retirees for material and spiritual life. As some of the older comrades grew older, their health deteriorated. Some frail old comrades have long been hospitalized or sick at home, unable to take care of themselves, and the difficulties have gradually increased. However, there is no corresponding increase in the retirement management and it is difficult to provide more attentive services. After some personnel retreated, they left their former residence and were scattered in major cities or even abroad. This caused scattered families, wide areas, difficult communication and other problems, to some extent, it also brought difficulties to management. The University also retired in the organization to carry out activities, means and form is relatively single, often confined to dinners, outings and other activities, and ignore the pursuit of retirees on the quality of spiritual life, it is difficult to fully mobilize the retired personnel to actively participate in the activities of interest. Strengthening the information construction of retirement work archives management. Along with the digital campus gradually formed, the retired college archives management should make full use of the advantages of the campus network and digital campus construction time, the use of modern information technology to strengthen the archives information resources collection, collation, development and utilization, promote the process of information from the archives management work of retirement. According to the relevant standard of information management of the school archives, the development or purchase of relevant software, establish and improve the retired workers 
information database, establish retired work into the local area network, campus network, and gradually realize the archives information transmission network and online service utilization, improve work efficiency, realize the sharing of information resources to promote the process of digital and network management into the colleges.

\section{Reform Measures of Management and Service for College Retirees in the New Era}

Improve Management System. We should make the management of University retirees be humane, standardized and institutionalized through the innovation and construction of the system, and implement the political and living treatment of the old comrades. To be consistent, concerted efforts in political thought respect, care, life care, all slightly first principle, establish practical and conducive to the promotion of physical and mental health of the retired personnel security mechanism and operation mechanism. The university can establish a chat room in the retired activity center, innovation chat system, improve briefings, visit condolences to retired personnel system; regular home about old comrades, need timely help, the old comrades thought and solve practical problems in life; in important festivals, major political activities and old comrades ill in hospital when arranged for their condolences. Its purpose is to promote the staff more clearly recognize their own duties, and according to the evaluation results to work and adjust the way of expression. Schools should establish a corresponding assessment mechanism to implement management and service work. First of all, the management and service contents of the existing specific division, different staff corresponding to different types of work, the retired personnel demand in the project can be the most fundamental and comprehensive protection. Secondly, through the establishment of performance appraisal mechanism, to achieve regular assessment of staff, so that they can solve their own problems and problem-solving ability and service attitude, there is a more comprehensive and perfect cognition. At the same time, those who work in the management of services in place to be commended, so that they make persistent efforts.

Promote Service Consciousness. Service consciousness is the idea and desire to do the work voluntarily. Service consciousness has strong and indifferent points, there are active and passive points. This is the degree of knowledge, deep understanding will have a strong sense of service; with a strong showing the individual talent, reflecting the value of life concept, will have a strong sense of service; a unit for the family, love the collective, style and spirit of selfless dedication, will have a strong sense of service. The connotation of service consciousness is that it is from the heart, and thus becomes the instinct and habit of management; it can be trained, educated and trained. The main features of the management of retirees are complex, tedious, repetitive and urgent, but only these can better serve retirees. Therefore, real feelings for the retired personnel to carry out the work, that is from the fine start, starting from the drip, think what they think they are worried, the only way to make the retirees feel the management work of the school and let them genuine and sincere, not as a whole and harmonious. To strengthen the construction of campus culture and education on Chinese national culture and helping respecting culture, let more students to actively participate in the retirees help and care of the team, to create a good and harmonious atmosphere to carry out specific work and implementation. Actively organize the enthusiastic students or young volunteers service team, the elderly retirees of in-depth, in the spirit of full of youthful spirit and public spirited auxiliary management services of their own development, and will bring more positive energy to the elderly, which was infectious. Only by improving the service consciousness of the staff can we really provide good service for retirees.

Establish Network Platform. The management of retired veteran comrades is a complex task. Therefore, the management should have the consciousness of innovation, with characteristics of retired veteran comrades, through visits, interviews and other forms of family chat, with their family members, children collect personal health, telephone, personal hobbies and other relevant information, the establishment of retired personnel information database and real-time update and backup using network technology. From the original passive service waiting for the door to the active home service change, from the general service to personalized service change, the implementation of 
dynamic management. For the old comrades in the activities of the allocation of computers, so that they understand the network through the domestic and international events, the establishment of older people's own web site, and open up the old university, sunset red and other columns to cultivate their interests and hobbies. Encourage old comrades to participate in the construction of websites and useful edutainment activities to enrich their later life, and make their life a sense of the times and enrichment. The management of College retirement should absorb the essence from the traditional management model, innovate and perfect it, and inject new forms and contents for the current management mode. It should be a gradual transition from the independent management of the school to the community and school management. Constructing a new mode of community and school management based on community management and supplemented by school management. No new thing can be smooth sailing. This new mode of retirement management in Colleges and universities has a period of adaptation before its formal production. Network construction can strengthen the old people's health care and medical health education, and improve their own health protection and nutrition health care ability. With the pace of reform and opening up, the needs of economic and social development and the maturity of the social security system. The transformation of this mode can be realized to a certain extent.

\section{Conclusion}

In a word, it is necessary to do a good job in the management and service of retirees to ensure the stability of retirees under the new situation. Therefore, the college administrators should renew their concepts and models. On one hand, they should transform the management system; on the other hand, they should raise their awareness of service. At the same time, the college administrators should make full use of the internet to provide convenient management and services for retirees in colleges.

\section{References}

[1] Shao Jie, Emotinal Management in Ideological Work of College Retired People [J]. The Guide of Science \& Education, 2015(8): 76-77.

[2] Zheng Lihua, Some reflections on improving management service level of college retired personnel [J]. Heilongjiang Science, 2016, 7(10): 98-99.

[3] Yang Guohua, Discussion on the Management of Retirement Affairs at Colleges [J]. Journal of Nanjing Institute of Technology (Social Science Edition), 2010, 10(2): 65-68.

[4] Li Jinhua, Thoughts and Countermeasures of Party Branch Construction for Retired Cadres at Colleges and Universities in the New Period [J]. Journal of Hefei University of Technology (Social Sciences), 2013, 27(6): 126-129. 